\title{
Back to the Basics: Thyroid Gland Structure, Function and Pathology
}

\author{
JANELLE M. CHIASERA
}

\section{LEARNING OBJECTIVES}

1. Explain the HPT feedback system involving the thyroid gland. Include the hormone produced from each gland and the effect of that hormone on the other unit.

2. Describe thyroid hormone synthesis including a description of the 5 steps of hormone production and the rate limiting step to the production of thyroid hormones.

3. Differentiate between hyperthyroidism and hypothyroidism including associated laboratory data, signs and symptoms presented, primary cause, and treatment.

4. Explain the importance of neonatal screening and indicate the type of screening method used by the U.S.

5. Explain the difference between overt and subclinical thyroid disorders and euthyroid sick syndrome and explain what the laboratory data would look like in both conditions.

ABBREVIATIONS: AAP - American Academy of Pediatrics; DIT - diiodotryrosine; fT3 - Free T3; fT4 Free T4; HPT - hypothalamus, pituitary, thyroid axis; MIT - monoiodotryrosine; rT3 - reverse T3; ESS euthyroid sick syndrome; T3 - triiodothyronine; T4 thyroxine; TBG - thyroxine-binding globulin; TBPA thyroxine-binding prealbumin; THBR - thyroid hormone binding ratio; TRH - thyrotropin-releasing hormone; TSH - thyroid stimulating hormone; TT3 total T3; TT4 - total T4

INDEX TERMS: Thyroid, Hyperthyroidism, Hypothyroidism, Grave's Disease, Hashimoto's Thyroiditis, Antithyroid Agents

Clin Lab Sci 2013;26(2):112

Janelle M. Chiasera, PhD, MT (ASCP), University of Alabama at Birmingham, Birmingham, Alabama
Address for Correspondence: Janelle M. Chiasera, PhD, MT(ASCP), Chair and Professor, University of Alabama at Birmingham, 1705 University Blvd, SHPB 431, Birmingham, Alabama 35294, 205-975-3111, chiasera@uab.edu

The thyroid gland is one of many glands associated with the endocrine system and it is responsible for the production and secretion of the thyroid hormones, triiodothyronine $\left(\mathrm{T}_{3}\right)$ and thyroxine $\left(\mathrm{T}_{4}\right)$. The thyroid gland is located at the front of the neck and is bilobular in structure such that it has a butterfly appearance. The thyroid gland is made up of two cell types, follicular and parafollicular cells. The follicular cells are responsible for producing thyroid hormones. The follicular cells enclose a space called the colloid which contains stored thyroglobulin, a glycoprotein that contains the precursors $\mathrm{T}_{3}$ and $\mathrm{T}_{4}$. The parafollicular cells, also known as C-cells, secrete the hormone calcitonin, a hormone responsible for the regulation of calcium. ${ }^{1-3}$

The thyroid gland, like other glands of the endocrine system, is controlled through a feedback system involving the hypothalamus, the pituitary, and the target gland (the thyroid). The relationship between the hypothalamus, the pituitary and the thyroid gland is referred to as the HPT axis. The hypothalamus is responsible for producing thyrotropin-releasing hormone (TRH), a tripeptide which is secreted into the venous system that drains to the pituitary gland. At the pituitary, TRH binds to receptors in thyrotroph cells causing the production and secretion of thyroid stimulating hormone (TSH), also known as thyrotropin. Thyroid stimulating hormone binds to TSH receptors in the follicular cells of the thyroid gland causing the production and secretion of thyroid hormones, $\mathrm{T}_{3}$ and $\mathrm{T}_{4}$. As with all endocrine glands, the thyroid gland exhibits both negative and positive feedback; however, the negative feedback system predominates. In negative feedback, the hormones 
produced by the thyroid gland negatively feed back to the hypothalamus and pituitary to shut off any further production of thyroid hormones. This negative feedback is ultimately responsible for maintaining relatively constant levels of circulating hormones. Refer to Figure $1 .^{1-3}$

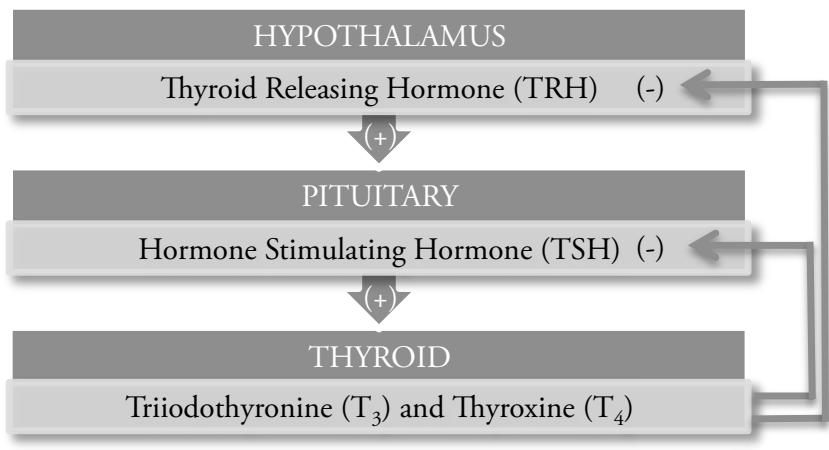

Figure 1. HPT axis for the thyroid gland showing positive (+) and negative (-) feedback

Thyroid hormone synthesis takes place in the follicular cells of the thyroid gland. It involves multiple steps including iodide trapping, organification, coupling, storage, and secretion. Iodine is essential for the production of thyroid hormones and is considered the rate-limiting step in production of thyroid hormones. The energy dependent trapping of iodide occurs in the follicular cell (iodide trapping). Once in the follicular cell iodide is oxidized to iodine, it combines with tyrosine residues within thyroglobulin (TG) to form monoiodotyrosine (MIT) and diiodotyrosine (DIT) (organification). Enzymatic coupling of MIT and DIT takes place producing intrathyroglobulin $T_{3}$ and $T_{4}$ which is released from the follicular cell for storage in the colloid (coupling and storage). This serves as a ready storage pool of thyroid hormones. Upon stimulation by $\mathrm{TSH}$, drops of colloid are engulfed by the follicular cells and are digested by proteases, which releases $T_{3}, T_{4}$, MIT, and DIT. The MIT and DIT molecules are rapidly deiodinated and their iodine is reutilized for subsequent hormone synthesis. $\mathrm{T}_{3}$ and $\mathrm{T}_{4}$ are resistant to deiodination and are secreted from the follicular cell into the circulation..$^{1-3}$ Refer to Figure 2.

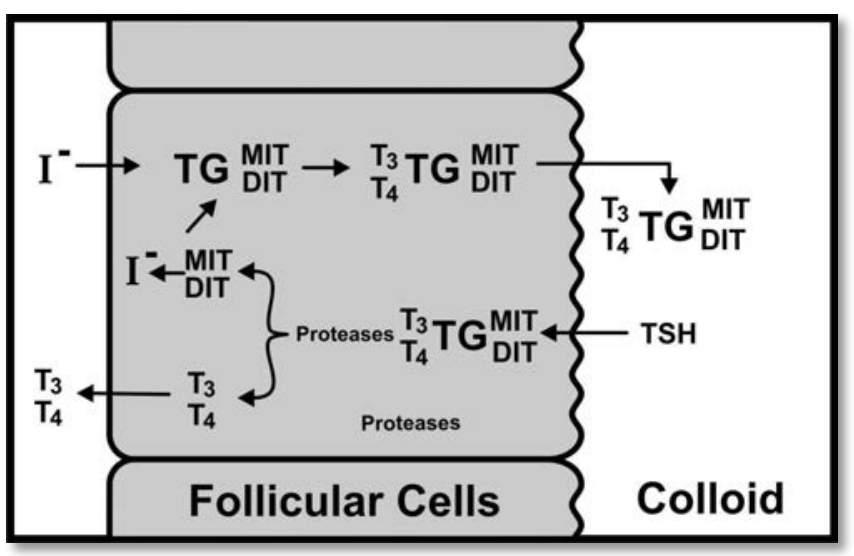

Figure 2. Synthesis of Thyroid Hormones. Image reprinted with permission of John Nagy.

Both $T_{3}$ and $T_{4}$ are produced from the thyroid gland; however, $\mathrm{T}_{3}$ and $\mathrm{T}_{4}$ are not produced in equal amounts. All of $T_{4}$ is produced in the thyroid gland while only $20 \%$ of $\mathrm{T}_{3}$ is produced directly from the thyroid gland. The other $80 \%$ of $\mathrm{T}_{3}$ is produced from the extrathyroidal deiodination of $\mathrm{T}_{4}$. The extrathyroidal deiodination occurs mainly by the liver and/or the kidneys. The deiodination of the outer ring of the T4 molecule results in the production of $\mathrm{T} 3$ and the deiodination of the inner ring of the $\mathrm{T} 4$ molecule results in the production of reverse T3 (an inactive compound). Refer to Figure 3. Although the principal thyroid hormones are $T_{3}$ and $T_{4}$, there is evidence to suggest that only $\mathrm{T}_{3}$ has hormonal activity, therefore $\mathrm{T}_{4}$ serves as a prohormone. ${ }^{1-4}$<smiles>NC(Cc1cc([123I])c(Oc2cc([123I])c(O)c([123I])c2)c([125I])c1)C(=O)O</smiles>
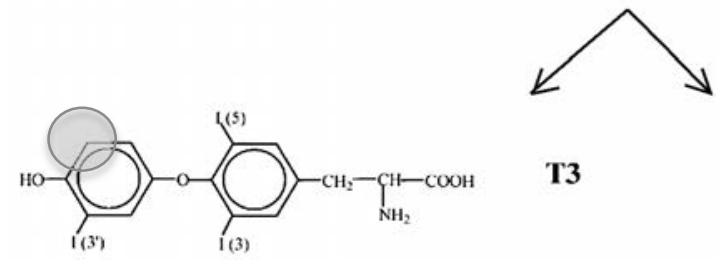

T3

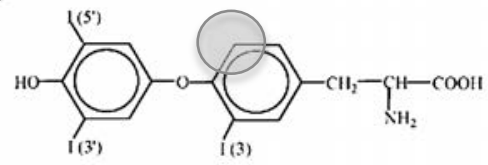

rT3

Figure 3. Deiodination of $\mathrm{T}_{4}$ at an outer ring to produce $\mathrm{T} 3$ and the inner ring to produce $\mathrm{rT} 3$. Highlighted areas represent the deiodination sites. 
Once produced, thyroid hormones circulate bound to one of three plasma proteins, thyroxine binding globulin (TBG), thyroxine binding prealbumin (TBPA), and albumin. Most of $\mathrm{T}_{3}$ and $\mathrm{T}_{4}$ circulate bound to TBG and to a much lesser extent they circulate bound to TBPA and albumin. Refer to Table 1. $T B G$ has the greatest affinity for $T_{3}$ and $T_{4}(K=$ $10^{10}$ ), has one single binding site per molecule, and circulates in the lowest concentrations $(0.37 \mu \mathrm{M})$. Thyroxin binding prealbumin has an intermediate affinity for $T_{3}$ and $T_{4}(K=107)$ and circulates in moderate concentrations $(4.6 \mu \mathrm{M})$. Albumin has the lowest affinity for $\mathrm{T}_{3}$ and $\mathrm{T}_{4}\left(\mathrm{~K}=10^{5}\right)$, has multiple binding sites per molecule, and circulates in the body in high concentrations $(590 \mu \mathrm{M}))^{1-3}$

Table 1. Thyroid binding proteins

\begin{tabular}{ccc}
\hline Binding Protein & T3 Bound (\%) & T4 Bound (\%) \\
TBG & $80 \%$ & $60-70 \%$ \\
TBPA & $9 \%$ & $15-30 \%$ \\
Albumin & $11 \%$ & $10 \%$ \\
\hline
\end{tabular}

\section{Thyroid Hormone Function}

Thyroid hormones have widespread function effecting metabolism, growth and maturation, and other organspecific effects. From a metabolic perspective, thyroid hormones are calorigenic in nature and result in oxygen consumption and the generation of body heat. They increase protein catabolism, promote gluconeogenesis, increase the utilization of glucose and promote lipid metabolism. With regard to other organ-specific effects, thyroid hormones influence cardiac function by increasing heart rate, myocardial contractility, blood volume, and cardiac output while decreasing peripheral vascular volume. They stimulate the production of cytokines, growth factors and other factors to stimulate bone development and growth. Thyroid hormones also promote increased motility in the gastrointestinal system and increase adrenergic activity and sensitivity in the central nervous system. Because they also promote cell differentiation, growth and maturation thyroid hormones are essential in early fetal life to promote normal growth and brain development. ${ }^{1-2}$

Given the widespread function of thyroid hormone, deficiencies and elevations in hormone levels cause many clinical signs and symptoms. These deficiencies or elevations cross multiple organ systems causing great discomfort for those with associated abnormalities. However, depending on the severity of the disease the signs and symptoms may be absent to full blown in nature. Refer to Table 2 for a list of usual signs and symptoms for those with hyperthyroidism and hypothyroidism. ${ }^{1-2}$

\section{Thyroid Pathology}

Disorders of the thyroid gland are usually described by the level of circulating hormone. Hyperthyroidism occurs when there is an overproduction of thyroid hormones and hypothyroidism results when there is an under production of thyroid hormones. These disorders are further categorized by the endocrine gland causing the disorder being further classified as primary, secondary, or tertiary. Diseases categorized as primary arise from a disorder with the thyroid gland, while those categorized as secondary or tertiary arise from damage to the pituitary and hypothalamus gland, respectively. Disorders of the thyroid gland include hypothyroidism, hyperthyroidism, euthyroid sick syndrome, and those resulting from medications. In addition, due the recent advances in highly sensitive assays to detect thyroid stimulating hormone, disorders may also be categorized as overt or subclinical. Subclinical disorders are identified before the signs and symptoms appear in the patient and before thyroid hormone levels are abnormal. The only abnormality seen in subclinical disorders is an abnormality with TSH values. Thyroid hormone levels will be normal in these cases. Overt cases present with clinical signs and symptoms and abnormalities in TSH and thyroid hormone levels. ${ }^{5}$

Table 2. Usual signs and symptoms seen with hyperthyroidism and hypothyroidism

$\begin{array}{cc}\text { Hyperthyroidism } & \text { Hypothryoidism } \\ \text { Heat intolerance } & \text { Cold intolerance } \\ \text { Flushed skin } & \text { Dry skin } \\ \text { Increase appetite } & \text { Lethargy } \\ \text { Muscle wasting } & \text { Generalized weakness } \\ \text { Weight loss } & \text { Weight gain } \\ \text { Exopthalmus } & \\ \text { Heart palpitations } & \\ \text { Tachycardia } & \text { Bradycardia } \\ \text { Shortness of breath } & \text { Heart enlargement } \\ \text { Restlessness } & \text { Apathy } \\ \text { Nervousness } & \text { Mental sluggishness } \\ \text { Fatigue } & \text { Mental retardation } \\ \text { Hyperdefecation } & \text { Constipation }\end{array}$




\section{Hypothyroidism}

Hypothyroidism occurs when there are insufficient thyroid hormones available to the tissues. The majority of hypothyroid cases are primary in nature meaning that they arise from a disorder from the thyroid gland itself such as conditions or treatments that destroy thyroid tissue or interfere with thyroid hormones production. To a much lesser extent they may be due to pituitary and/or hypothalamic disease that results in TSH and/or TRH deficiencies. Refer to Table 3 for the causes of hypothyroidism and hyperthyroidism. Autoimmune thyroiditis, also known as Hashimoto's thyroiditis, is the most common cause in iodine-sufficient areas. Hashimoto's thyroiditis is caused by the autoimmune destruction of thyroid tissue leading to thyroid gland inflammation and reduced thyroid hormone production. Because this disorder is autoimmue in nature, it frequently occurs with other diseases that are immune in nature and often presents with circulating antithyroid antibodies. Approximately $2-15 \%$ of the population is afflicted with this disorder and it carries a gender bias as it is seen more frequently in women. ${ }^{1-3,6}$

Table 3. Causes of Hypothyroidism and Hyperthyroidism

\begin{tabular}{ll}
\hline $\begin{array}{c}\text { Disorder } \\
\text { Hypothyroidism }\end{array}$ & \multicolumn{1}{c}{ Causes } \\
& Autoimmune thyroiditis (Hashimoto's) \\
Iatrogenic (treatment related) & Post-thyroidectomy \\
& Post-radioactive iodine treatment \\
Transient thyroiditis & Congenital hypothyroidism \\
& Iodine deficiency \\
& Drugs \\
& Autoimmune (Grave's) \\
& Thyroiditis \\
Hyperthyroidism & Nodular disease \\
& TSH producing pituitary adenoma \\
& hCG-mediated \\
& Exogenous thyroid hormone intake
\end{tabular}

When the disorder is overtly expressed, signs and symptoms will likely be presented in conjunction with elevated TSH and decreased $\mathrm{T}_{3}$ and $\mathrm{T}_{4}$ concentrations. In cases of subclinical hypothyroidism, signs and symptoms are not present, thyroid hormones are in the normal range, and only the TSH level is abnormal. Refer to Table 4. Treatment for those with hypothyroidism involves oral replacement through the drug levothyroxine. Oral replacement of thyroid hormones will reverse the laboratory finding and clinical signs and symptoms. ${ }^{1-3,7}$

Table 4. Common Laboratory Values seen in Hypothyroidism and hyperthyroidism

\begin{tabular}{lccc}
\hline \multicolumn{1}{c}{ Disorder } & TSH & fT4 & fT3 \\
$\begin{array}{l}\text { Primary Hypothyroidism } \\
\text { Subclinical }\end{array}$ & Increased & Normal & Normal \\
$\begin{array}{l}\text { Overt } \\
\text { Primary Hyperthyroidism }\end{array}$ & Increased & Decreased & Decreased \\
$\begin{array}{l}\text { Subclinical } \\
\text { Overt }\end{array}$ & Decreased & Decreased & Decreased \\
Decreased & Increased & Increased \\
\hline
\end{tabular}

An additional cause of hypothyroidism is neonatal hypothyroidism, also known as congenital hypothyroidism or cretinism. This disorder affects infants from birth and results from the complete absence of the thyroid gland (athyreosis) or it is secondary to defects in thyroid hormone synthesis. This disorder occurs in approximately 1 in $3500-4000$ live births and if left untreated can lead to profound mental retardation. Proper screening and initiation of therapy early, beginning within 2 weeks of age can normalize cognitive development and prevent the progression to profound mental retardation in infants with hypothyroidism. Because this is one of the most preventable causes of mental retardation, the American Academy of Pediatrics (AAP) recommended that all newborns be screened for hypothyroidism in 1993. Most newborn screening programs in the U.S. use the primary $\mathrm{TSH} /$ backup $\mathrm{T}_{4}$ screening method performed on filter-paper-blood-spots usually collected before discharge (optimally between 48 hours and 4 days of age); however other screening methods exist. Treatment for infants with hypothyroidism involves replacement therapy $(10-15 \mu \mathrm{g} / \mathrm{kg}$ depending on severity) to normalize $\mathrm{T}_{4}$ within 2 weeks and TSH within 1 month. In addition, the AAP recommends that infants being treated for hypothyroidism receive clinical examinations including assessment of growth and development every few months for the first 3 years of life and regular assessment of $\mathrm{T}_{4}$ and TSH as detailed in Table 5. The aim of therapy is to ensure normal growth and development through maintenance of $\mathrm{T}_{4}$ and TSH in the upper half of the reference interval (optimally 0.5 $2.0 \mathrm{mU} / \mathrm{L}) .^{1-3,8}$

\section{Hyperthyroidism}

Hyperthyroidism occurs when there is an excessive 
production of thyroid hormones and may be caused by a variety of conditions (Table 3). The term thyrotoxicosis is used to describe the clinical state of high thyroid hormone concentrations. The most common cause of hyperthyroidism (thyrotoxicosis) in the U.S. is Grave's disease. Grave's disease represents an autoimmune disorder where the antibodies produced are directed against the TSH receptors in the thyroid gland causing an overproduction of $\mathrm{T}_{3}$ and $\mathrm{T}_{4}$. Grave's disease has a low prevalence rate in the population $(0.3$ $-0.6 \%)$ and occurs more frequently in women.

Table 5. T4 and TSH assessment in Infants treated for Hypothyroidism

Time Period

2-4 weeks after initiation of treatment

Every 1 to 2 months during first 6 months of life

Every 3 to 4 months between 6 months -3 years

Every 6 to 12 months until growth in completed

More frequently when warranted

When hyperthyroidism is overtly expressed, signs and symptoms will likely be presented in conjunction with decreased TSH and increased $\mathrm{T}_{3}$ and $\mathrm{T}_{4}$ concentrations. In cases of subclinical hyperthyroidism, thyroid hormones are in the normal range, and only the TSH level is abnormal. Refer to Table 4. Treatment for hyperthyroidism may involve the use of antithyroid drugs to inhibit the production of thyroid hormones or surgical thyroidectomy or radioactive iodine to reduce the hyperfunctioning thyroid tissue. Often physicians will prescribe $\beta$-blockers to help suppress the symptoms of hyperthyroidism until the other treatments take effect. While on antithyroid drugs it is recommended that free-T4 (fT4) be monitored 4 weeks after initiation of therapy and at intervals of 4-8 weeks until euthyroid levels are achieved.?

\section{Euthyroid Sick Syndrome}

Abnormal thyroid hormone levels may occur without the presence of thyroid disease. This is particularly common in hospitalized patients and is often due to alterations in the concentration of hormone binding proteins, the actions of certain drugs, effects of nonthyroidal illnesses, or peripheral resistance to thyroid hormones. Conditions resulting in abnormal thyroid hormones in the absence of thyroid disease are referred to as Euthyroid Sick Syndrome or low $\mathrm{T}_{3}$ syndrome. This syndrome is characterized by decreased $\mathrm{T}_{3}$ levels coupled with an elevation in reverse $\mathrm{T}_{3}$. TSH levels in this condition vary from high-normal to high and T4 values are of little clinical value as they are variable in their levels during this syndrome. As patients recover from these illnesses the thyroid laboratory tests appear to return to normal; therefore, assessments of thyroid status should be performed when illnesses subside, unless deemed necessary for a patient outcome. $^{10}$

\section{Laboratory Tests}

There are often issues between clinical findings and laboratory testing that make the diagnosis of thyroid disorders (and endocrine disorders) challenging. The overall goal of screening for thyroid disease is to identify and treat patients at risk for the consequences of thyroid dysfunction before the disorders become clinically apparent. Screening for thyroid dysfunction should be performed using a medical history, physical examination, and laboratory tests. However, there are a variety of laboratory tests that have been developed to measure thyroid function including $\mathrm{TSH}$, free $\mathrm{T} 4$ (fT4), total T4 (TT4), free T3 (fT3), total T3 (TT3), thyroxine-hormone binding ratio ( $\mathrm{THBR}$ ), reverse $\mathrm{T} 3$ (rT3), and index methods. Recent advances in laboratory testing have shifted diagnostics to a TSH centered approach for the detection of thyroid disorders. High sensitive TSH assays are now the recommended initial screening test to detect thyroid disorders and fT4 and/or fT3 can be used as reflex testing as applicable. This TSH-centered approach for the evaluation of thyroid function is both cost effective and efficient. ${ }^{1-3,11}$

\section{Conclusion}

The thyroid gland is a complex endocrine organ that has widespread function and control over multiple organ systems and processes. It functions through an elaborate connection between the hypothalamus, pituitary, and the thyroid gland to maintain normal levels of circulating hormones. High and low levels of thyroid hormones can lead to abnormalities such as hypo- and hyperthyroidism that arise from a variety of causes, the most common being Hashimoto's thyroiditis (hypothyroidism) and Grave's disease (hyperthyroidism). The laboratory plays an important role in the treatment and diagnosis of thyroid disorders as sensitive TSH tests can be used to detect disorders before the 
signs and symptoms of the disorders appear. Current recommendations to evaluate thyroid function have progressed from thyroid panel testing to a TSH centered approach that is more cost effective and medically efficient.

\section{REFERENCES:}

1. Clines G, Demers L, General Endocrinology. In: Kaplan L, Pesce A. eds. Clinical Chemistry: Theory, Analysis, Correlation. $5^{\text {th }}$ ed. St. Louis:Mosby Inc.; 2010.

2. Kleerekoper M. Hormones. In: Burtis C., Ashwood E., Bruns D. eds. Tietz Fundamentals of Clinical Chemistry. $6^{\text {th }}$ ed. Philadelphia:W.B. Saunders Company;2008.

3. Bertholf R. Laboratory Evaluation of Thyroid Function. In: Clarke W. ed. Contemporary Practice in Clinical Chemistry. $2^{\text {nd }} \mathrm{ed}$. Washington, DC:AACCPress;2011.

4. Liu Y, Brent G. Thyroid hormone crosstalk with nuclear receptor signaling in metabolic regulation. Trends Endocrinol Metab 2012;21:166-73.

5. U.S. Prevention Services Task Force. Screening for Thyroid
Disease: Recommendation Statement. Ann Intern Med. 2004; 140(2):125-7.

6. Ridgeway E. Modern concepts of primary gland failure. Clinical Chemistry, 1996;42:179-82.

7. Brent G. Larsen P, Davies T. Hypothyroidism and thyroiditis. In: Kronenberg. Melmed S. Polonsky K., Larsen P, eds. Williams Textbook of Endocrinology. 11th ed. Philadelphia: Saunders Elsevier; 2008.

8. American Academy of Pediatrics and Pediatric endocrine Society. Update of newborn screening and therapy for congenital hypothyroidism. Pediatrics, 2006;117:2290-303.

9. Bahn R, Burch H, Cooper D, Garber J, et al. Hyperthyroidism and other causes of thyrotoxicosis: management guidelines of the American thyroid association and American association of clinical endocrinologists. Thyroid, 2010;21(6):593-646.

10. Mclver B, Gorman C. Euthyroid Sick Syndrome: an overview. Thyroid, 1997;(1);125-32.

11. Spencer C, Lopresti J, Middlesworht L, et al. Screening for thyroid dysfunction: which test is best. JAMA, 1993;270:22978.

\section{ASCLS Online CE - Expand Your Knowledge!}

Vitamin D Regulation, Clinical Significance and Treatment $\infty$ authored by expert Hershel Raff, PhD, Endocrine Research Laboratory, St. Luke's Medical Center, Milwaukee

\section{Sexually Transmitted Bacterial Infections} $\infty$ authored by expert Lynda Britton, PhD, MLS(ASCP) ${ }^{\mathrm{CM}}$, Professor,

LSU Health Science Center Shreveport

Two of many online learning experiences

Easy to navigate courses

Learn at your own pace

Earn P.A.C.E. ${ }^{\oplus}$ credit

For more information, go to www. ascls.org/store and select Online Learning category in the Merchandise area. 